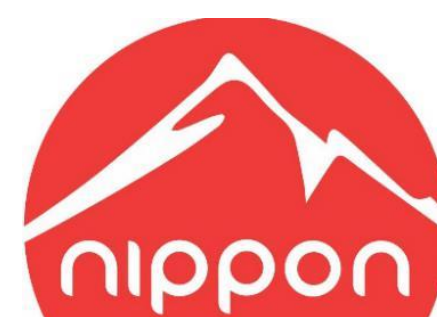

PUBLICATION

Full Length Research Paper
Nippon Journal of Environmental Science

ISSN: 2435-6786

2020; 1(9): 1021

https://doi.org/10.46266/njes.1021

(C) 2020 by Authors

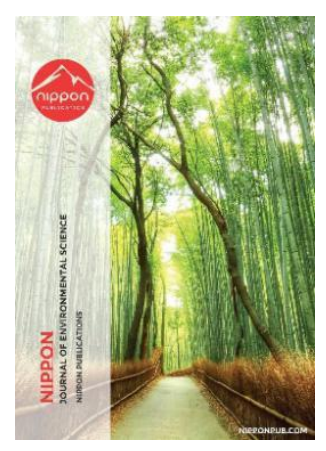

\title{
Morphological diversity of the populations of Balanites aegyptiaca L. Del in the Ferlo River in northern Senegal
}

\author{
Alimatou Sam ${ }^{1}$, Moustapha Bassimbé Sagna ${ }^{1}$, Mariama Dalanda Diallo ${ }^{2,4,5}$, Aly Diallo ${ }^{3}$, Papa Saliou SARR ${ }^{6}$, \\ Sekouna Diatta ${ }^{1}$, Deborah Goffner ${ }^{5}$, Aliou Guissé ${ }^{1,4,5^{*}}$
}

${ }^{1}$ University Cheikh Anta Diop, Department of Plant Biology, Faculty of Science and Technology, PO Box: 5005 Fann, Dakar, Senegal

${ }^{2}$ University Gaston Berger de Saint Louis, UFR of Agronomic Sciences, Aquaculture and Food Technologies, PO Box: 234 Saint Louis, Senegal

${ }^{3}$ Assane Seck University, Ziguinchor-Senegal, Department of Agroforestry, PO Box: 523 Néma, Ziguinchor, Senegal

${ }^{4}$ Tessékéré Middle Man Observatory, Senegal, UCAD / CNRS, Dakar, Senegal

${ }^{5}$ United International Joint Unit 3189 "Environment, Health, Society", Dakar, Senegal

${ }^{6}$ Japan International Research Center for Agricultural Sciences (JIRCAS) 305-8686 Ibaraki, Tsukuba, Owashi 1-1, Japan

*Corresponding Author: Tel.: (+221) 776389669; e-mail: aliou.guisse@ucad.edu.sn

Received 01 August 2020; Accepted 10 January 2021

\begin{abstract}
The objective of this work is to evaluate the morphological variability of the population of Balanites aegyptiaca (L.) Del. for a better valorization of its resources in a semi-arid zone of Senegal where the species plays an important role in the daily life of the local populations. The choice of study sites took into account the variability of soils and climates in the area. The morphological characterization of individuals was carried out following a methodological approach using a system of descriptors divided into three groups of parameters (dendrometric, fruit and leaves). The inventoried individuals were of breeding age and at least 100 meters apart. They were distributed in three sites arranged on an increasing rainfall gradient Koyli alpha, Labgar and Ranerou. The results obtained showed the influence of variability linked to environmental conditions on the morphological characteristics of the species. However, a lack of correlation between groups of descriptors (dendrometric, fruit and leaf) was observed. However, the fruit descriptors were more discriminating. They made it possible to identify individuals within the studied population that could be of interest for a varietal selection program given the morphology and mass of the fruits they produce. These individuals could be influenced by climatic determinism, since they are mostly found at the wettest site of the transect. The information obtained from this work could be useful to meet the needs for local valorization of the plant's resources.
\end{abstract}

Keywords: Descriptors, Morphology, Balanites aegyptiaca, Ferlo, Senegal

\section{INTRODUCTION}

Balanites aegyptiaca (L) Del. is a woody member of the family Zygophyllaceae. Commonly called desert date palm, it is among the plant species that characterize the Sahelian environment (Hall and Walker, 1991). In Senegal, Ferlo is the preferred area for desert date palm (Sagna et al., 2014b). The plant is particularly adapted to the climate, its fruits have a great nutritional potential (Sagna et al., 2014a) appreciated by local populations, in addition to its uses in traditional medicine (Sagna et al., 2014b). Long considered as a simple subsistence product, the fruit of $B$. aegyptiaca is today the subject of speculation due to the economic stakes related to its nutritional and cosmetic importance because of the oils extracted from its kernel (Sagna, 2015).

Given its potential, B. aegyptiaca is considered among the agroforestry trees to be domesticated for the socioeconomic development of arid regions. Genetic studies on the plant have revealed a total diversity of $81.5 \%$ over its range, with very high rates of polymorphism of around $85 \%$ on average in Sahelian populations (Chevallier et al., 2003). In sub-Saharan Africa, a number of studies have contributed to a good knowledge of the plant's genetic resources, for a better valorization of its potential (Abasse et al., 2011; Elfeel and Hindi, 2014; Abdoulaye et al., 2016; Abdou Habou et al., 2020). In the Ferlo, 94\% of the people surveyed mentioned the existence of morphotypes within the B. aegyptiaca population (Sagna et al., 2014b). However, no further investigation was made on the study of the natural variability of the species in this area. The analysis of the morphological structuring of the species' 
populations in this area could be useful in order to optimize the value of the plant's resources or to identify potential individuals that could be targeted by a varietal selection program. The objective of this study is to make a morphological description of the populations of the species in the Ferlo using descriptors.

\section{MATERIALS AND METHODS}

\subsection{Presentation of the study area}

The study was carried out in three ( 3 sites) of Ferlo: Ranerou, Labgar and Koyli Alpha (Figure 1). These three sites are located on the route of the Great Green Wall (GMV). The choice of these sites is mainly motivated by the presence of a large population of Balanites aegyptiaca and the existence of a North / South rainfall gradient (Koyli Alpha, Labgar and Ranerou).

Ferlo has two well-marked seasons, a 9-month dry season (October - June) and a 3-month rainy season (July September). Between 1997 and 2017, the average intra-annual temperatures varied slightly between the sites, respectively $30.6^{\circ} \mathrm{C}, 29.4^{\circ} \mathrm{C}$ and $30.1^{\circ} \mathrm{C}$ in Koyli Alpha, Labgar and Ranerou. The rainfall variation follows the North / South gradient: Koyli Alpha (385.7 mm), Labgar (433.2 mm) and Ranerou (478.4 mm) (Kebe, 2019).

From a soil-morphological point of view, the sites studied are divided between two types of soil: red-brown soils and coarse-textured ferruginous soils found in the North-West part: Koyli Alpha and Labgar (MEPN, 2008; Kebe, 2019), and gravel soils with finer texture with, in places, lateritic outcrops that are found in Ranerou in the Southeast part (Leprun, 1971; Kebe, 2019).

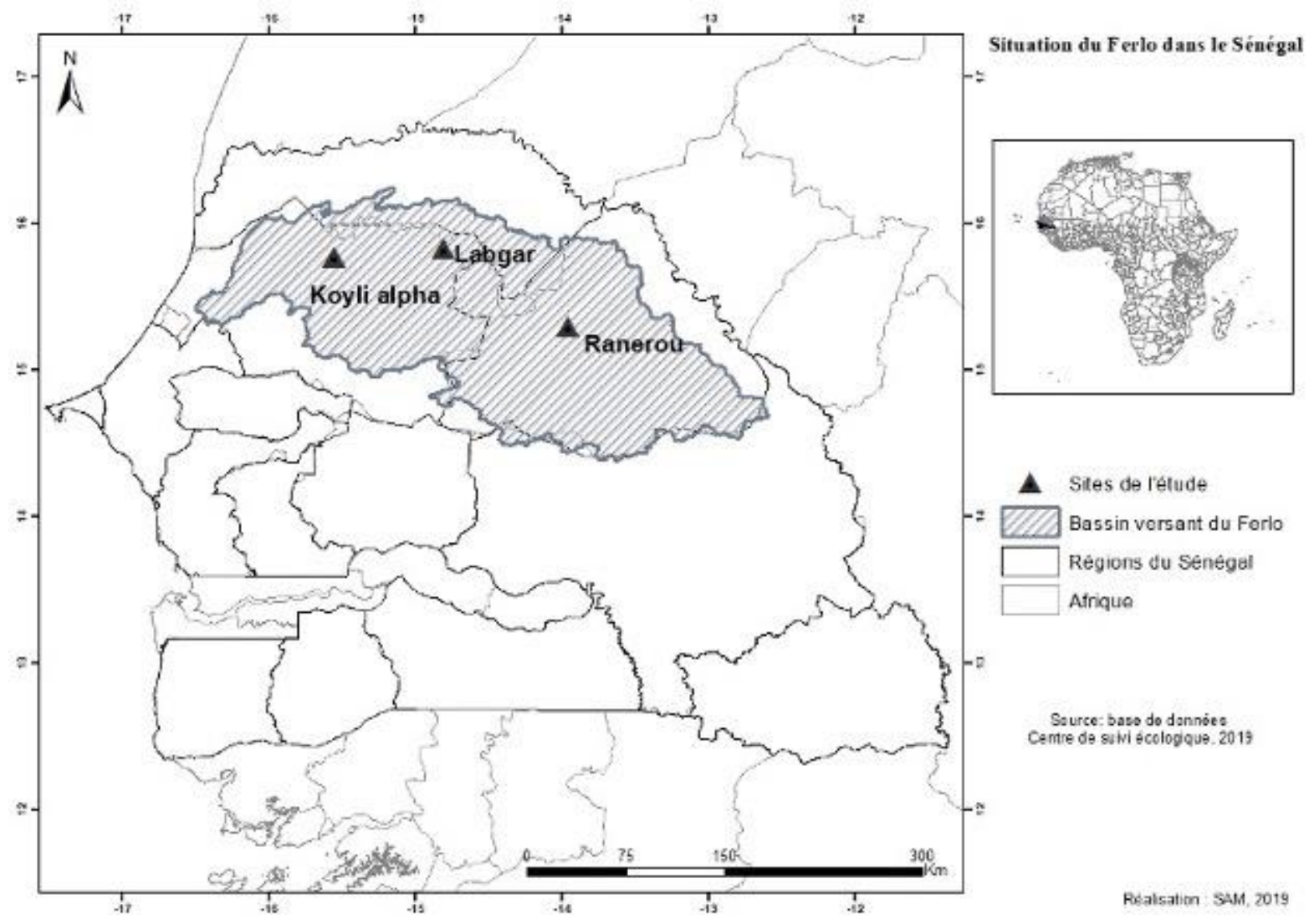

Figure 1: Geographic location of study sites (Sam, 2019)

\subsection{Biological material}

The date palm of the desert is a tree whose height varies between 5 and 10 meters (Figure 2a). Its branches are drooping, flexible, very branched and very thorny (Figure $2 b$ ). The leaves are alternate and inserted at the base of the thorns. The fruit is a largely oblong, ellipsoid drupe 2 to $4 \mathrm{~cm}$ long, yellow when ripe (Figure 2c). It has a thin epicarp covering a dark brown fleshy mesocarp with a very thick and hard endocarp containing an oil seed (Berhaut, 1979; Arbonnier, 2000). 


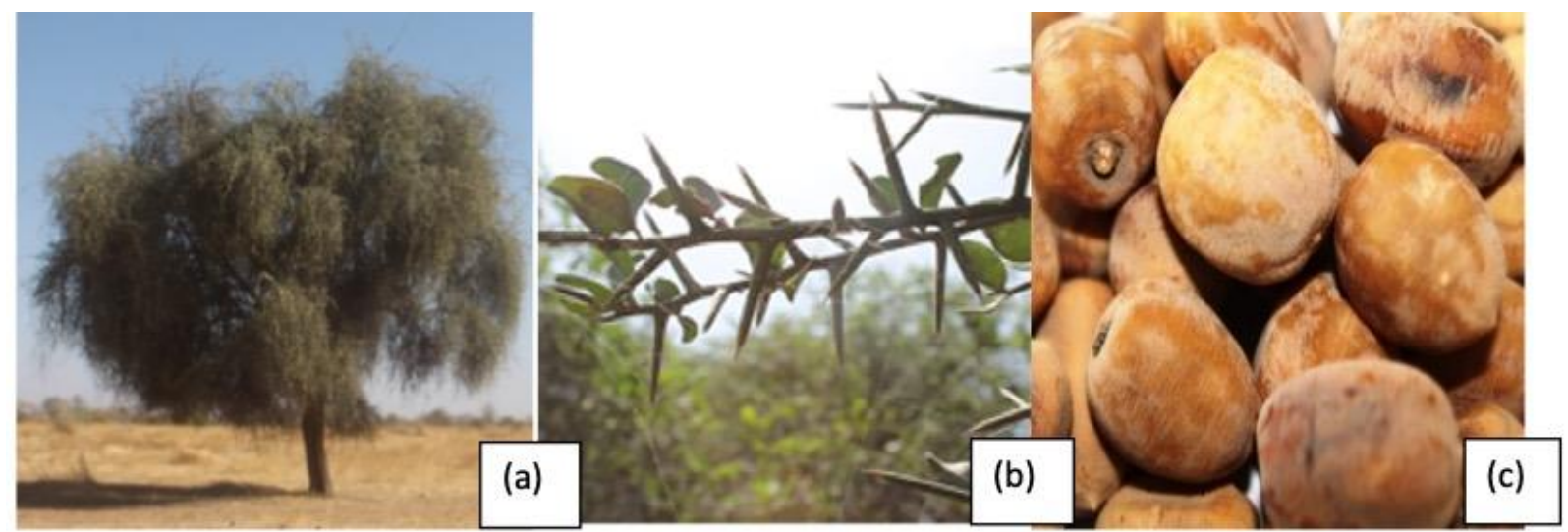

Figure 2: Some descriptive elements of Balanites aegyptiaca (L.) Del. (Photo M.B. Sagna, January 2011)

\subsection{Tree sampling}

The choice of trees was made according to their accessibility. The sampling method used is simple and random. In each site, individuals of fruit production age were selected. A sample of thirty (30) individuals was selected with a minimum spacing of 100 meters. These precautions were taken in order to avoid collecting material from genetically related individuals (Graudal, 1998; Abasse, 2011). For some individuals, it was possible to collect information during one or two trips. For others, however, regular monitoring was carried out over a period of 23 months following the phenological calendar of the species in the Ferlo.

\subsection{Morphometric characterization of samples}

The assessment of the morphological variability of Balanites aegyptiaca populations is carried out using a descriptor system (Kouyate, 2005; Abasse et al., 2010). This characterization involved ten morphological descriptors on dendrometric, foliar and fruit parameters. The dendrometric descriptors retained are: trunk diameter at $1.30 \mathrm{~m}$ from the ground (D 1.30), height of first branching (Hbr); total tree height (Ht) and crown diameter (Dhp). Leaf and fruit descriptors were applied to six (6) mature leaves and fruits randomly collected from each tree. On each leaf, three (03) variables were measured using a graduated ruler: the length and width of the leaf (L.fe and l.fe), the third variable being the ratio between length and width. The sampled fruits were dried to obtain a constant dry weight before measuring their length (L.fr), width (l.fr) using a slide rule (accuracy $\pm 0.1 \mathrm{~mm}$; figure $3 \mathrm{a}$ ) and their mass (M.fr) using a precision balance (accuracy $\pm 0.1 \mathrm{~g}$; figure $3 \mathrm{~b}$ ).

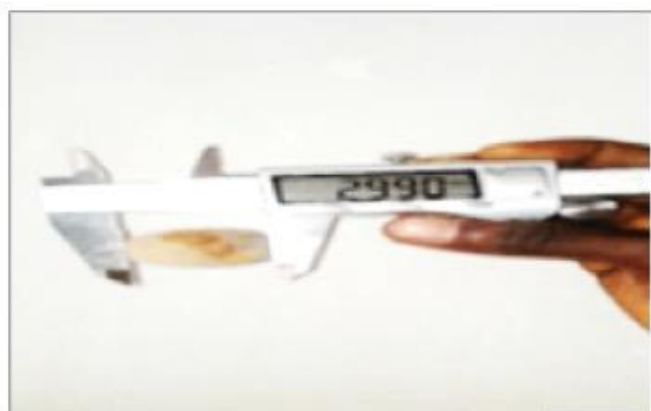

(a)

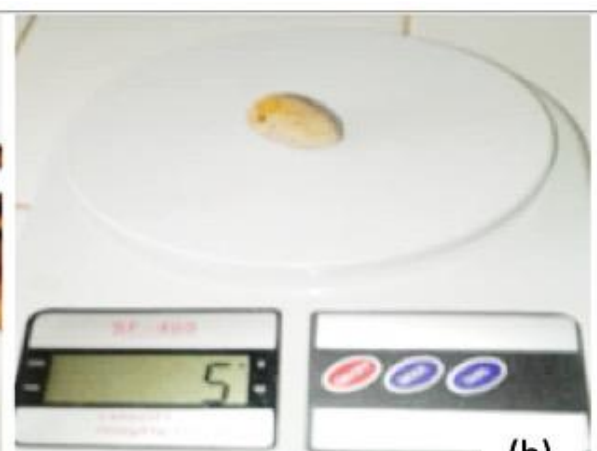

(b)

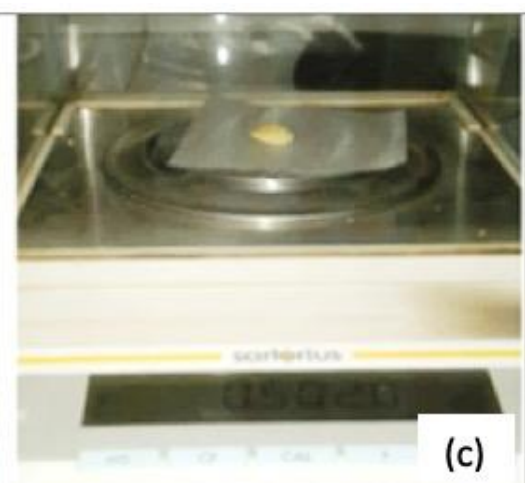

(c)

Figure 3: Measurement of dimensions and mass: using a sliding rule (a), a precision balance (b) and a Sartorius balance (c)

Each fruit is soaked in water for a few minutes and then pulped to isolate its kernel in order to measure its length (L.am) and width (L.am) and then weighed to determine its mass (M.am). To obtain the nut, the almond is crushed in order to extract its nut whose masses (M.n) are measured using a Sartorius balance (accuracy $\pm 0.01 \mathrm{~g}$; figure 3c). The mass of the pulp was determined by the difference between the mass of the fruit (M.fr) and the mass of its kernel (M.am); i.e. $\mathbf{M p}=$ M.fr - M.am (1) 


\subsection{Data processing}

Excel and Xlstat software were used for the statistical analyzes. The descriptors were then submitted to the Discriminant Component Analysis (AFD) and Principal Analysis (ACP) and to an Ascending Hierarchical Classification $(\mathrm{CAH})$ for the description of the date palm population.

\section{RESULTS AND DISCUSSION}

\subsection{Descriptive statistics of the measured parameters}

Table 1 summarizes data from statistical analyses of the measured morphometric parameters. Discriminant factor analysis is associated with descriptive statistics to identify the variables that best explain the morphological characteristics of date palm populations (Figure 4).

Table 1: Descriptive statistical analysis of measured parameters

\begin{tabular}{|c|c|c|c|c|c|c|c|c|c|c|c|c|}
\hline \multirow[b]{2}{*}{ Variable } & \multicolumn{3}{|c|}{ Ranerou } & \multicolumn{3}{|c|}{ Labgar } & \multicolumn{3}{|c|}{ Koyli Alpha } & \multicolumn{3}{|c|}{ Ferlo } \\
\hline & Average & $\begin{array}{c}\text { standar } \\
\mathrm{d} \\
\text { deviatio } \\
\mathrm{n} \\
\end{array}$ & CV (\%) & Average & $\begin{array}{c}\text { standar } \\
\mathrm{d} \\
\text { deviatio } \\
\mathrm{n} \\
\end{array}$ & $\mathrm{CV}(\%)$ & Average & $\begin{array}{c}\text { standar } \\
\mathrm{d} \\
\text { deviatio } \\
\text { ne }\end{array}$ & $\mathrm{CV}(\%)$ & Average & $\begin{array}{c}\text { standar } \\
\text { d } \\
\text { deviatio } \\
\text { ne }\end{array}$ & $\mathrm{CV}(\%)$ \\
\hline $\mathrm{D}_{1.3}(\mathrm{~m})$ & 37.55 & 12.26 & 32.64 & 27.92 & 9.03 & 32.35 & 33.86 & 11.03 & 32.56 & 32.58 & 11.31 & 34.71 \\
\hline $\operatorname{Hbr}(\mathrm{m})$ & 1.01 & 0.36 & 35.49 & 1.24 & 0.42 & 33.77 & 1.77 & 0.47 & 26.57 & 1.32 & 0.51 & 38.61 \\
\hline Dhp (m) & 8.13 & 2.32 & 28.47 & 7.02 & 1.55 & 22.11 & 9.29 & 2.15 & 23.11 & 8.01 & 2.17 & 27.09 \\
\hline $\mathrm{Ht}(\mathrm{m})$ & 8.58 & 1.43 & 16.63 & 8.04 & 1.52 & 18.95 & 9.54 & 1.95 & 20.42 & 8.63 & 1.72 & 19.91 \\
\hline 1.fe $(\mathrm{cm})$ & 1.92 & 0.51 & 26.34 & 2.24 & 0.67 & 30.11 & 1.73 & 0.47 & 27.25 & 1.99 & 0.60 & 30.25 \\
\hline L.fe (cm) & 3.15 & 0.63 & 19.98 & 3.57 & 0.86 & 24.21 & 3.37 & 0.70 & 20.64 & 3.38 & 0.76 & 22.49 \\
\hline L.fe/l.fe & 1.69 & 0.28 & 16.85 & 1.65 & 0.25 & 15.16 & 2.01 & 0.31 & 15.32 & 1.76 & 0.31 & 17.88 \\
\hline la.fr $(\mathrm{cm})$ & 1.92 & 2.08 & 10.84 & 1.76 & 1.56 & 8.90 & 1.75 & 2.61 & 14.90 & 1.80 & 2.17 & 12.01 \\
\hline L.fr (cm) & 2.46 & 3.45 & 14.01 & 2.39 & 2.76 & 11.52 & 2.52 & 4.17 & 16.59 & 2.45 & 3.41 & 13.91 \\
\hline Lfr/lfr & 1.29 & 0.18 & 14.25 & 1.37 & 0.16 & 11.90 & 1.46 & 0.28 & 18.94 & 1.37 & 0.21 & 15.60 \\
\hline 1.am (cm) & 1.31 & 1.42 & 10.86 & 1.23 & 1.38 & 11.24 & 1.28 & 2.00 & 15.61 & 1.27 & 1.60 & 12.63 \\
\hline L.am (cm) & 2.23 & 3.54 & 15.82 & 22.14 & 2.89 & 13.05 & 23.14 & 4.02 & 17.38 & 22.49 & 3.41 & 15.18 \\
\hline L.am/l.am & 1.73 & 0.30 & 17.46 & 1.82 & 0.27 & 14.66 & 1.84 & 0.40 & 21.53 & 1.80 & 0.32 & 17.66 \\
\hline M.fr (g) & 4.38 & 1.32 & 30.22 & 3.53 & 0.75 & 21.20 & 3.85 & 1.53 & 39.72 & 3.88 & 1.23 & 31.64 \\
\hline M.am (g) & 1.95 & 0.21 & 10.91 & 1.74 & 0.44 & 25.01 & 1.95 & 0.55 & 28.09 & 1.87 & 0.43 & 22.85 \\
\hline M.p (g) & 2.42 & 1.18 & 48.80 & 1.79 & 0.45 & 25.29 & 1.90 & 1.09 & 57.18 & 2,02 & 0.95 & 46.94 \\
\hline M.n (g) & 0.46 & 0.09 & 20.73 & 0.40 & 0.14 & 35.44 & 0.40 & 0.31 & 76.58 & 0.42 & 0.19 & 46.14 \\
\hline
\end{tabular}

CV: Coefficient of variation ; Dhp: Crown diameter ; Ht :Total height; D1.30 : Diameter at 1.30 m; Hbr: height of the first branch; Dhp: crown diameter; $1 . f e$ : leaf width; L.fe: length of leaves; la.fr: fruit width; L.fr: length of fruit; 1.am: width of the almond; L.am: length of the almond; M.fr: mass of the fruit; M.am: mass of almond; M.p: pulpe mass; M.n: mass of the nut

The first two AFD axes explain all of the variance obtained. The F1 axis alone explains about $80 \%$ of the total variability (Figure 4a). Projection of the sampled individuals onto the plane formed by the two axes produced Figure $4 \mathrm{~b}$, in which each colour represents a sampling site. The red dot represents the barycentre of the samples collected for each site.

The variables selected for the analysis of the results are those whose contribution to the SFM axes is higher than the average (30\%). Thus:

- The variables with a significant contribution on F1 are respectively Hbr (70.5\%), L.fe/l.fe (55.7\%), Dhp (37.5\%), Ht (35.4\%) and Lfr/lfr (35\%);

- Those making a significant contribution on F2 are respectively D1.30 (60.8\%), Dhp (49.2\%), 1.fe (46.3\%), M.fr (46\%), la.fr (44.7\%), M.p (42.2\%) M.am (38.8\%), L.fe (37.3\%), l.am (34.5\%) and Ht (34.3\%).

The distribution of point clouds on the AFD axes indicates the existence of close links between individuals and their sampling site (Figure 4b).

Towards the positive coordinates of the F1 axis, the majority of the individuals sampled in Koyli are individualized. These individuals are characterized by high values of dendrometric descriptors: very high position of 
the first living branch $(\mathrm{Hbr}=1.77 \pm 0.47 \mathrm{~m})$, trees with large tops $(\mathrm{Dhp}=9.29 \pm 2.15 \mathrm{~m})$ and large size $(\mathrm{Ht}=9.54 \pm$ $1.95 \mathrm{~m}$ ). Leaves produced by individuals at this site are longer than wide (L.fe/l.fe $=2.01 \pm 0.31 \mathrm{high}$ ).

The Koyli population contrasts respectively with those of Labgar and Ranerou, most of whose individuals are located on the negative coordinates of F1. The F1 axis could therefore indicate the moisture gradient of the transect studied.

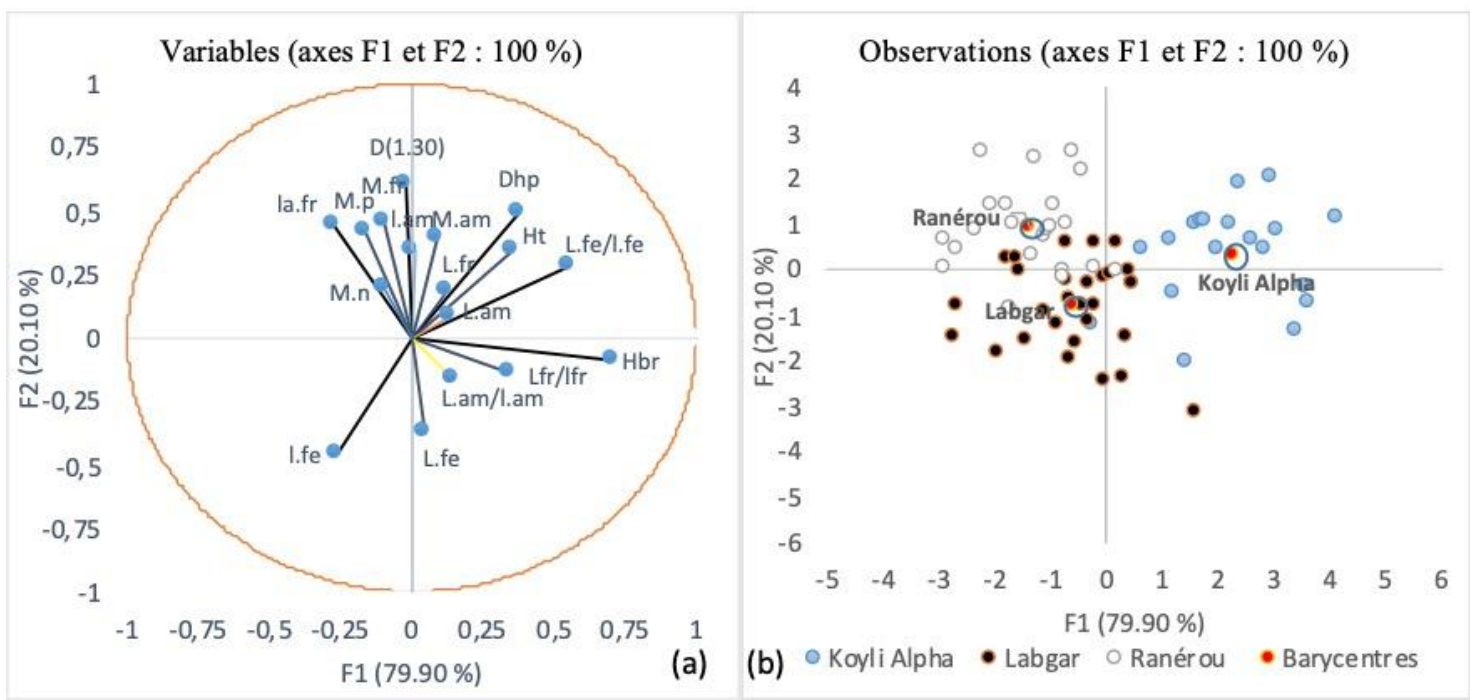

Figure 4: Representation of the variables (a) and representation of the individuals of each site (b) on the plane formed by the first two axes

Axis F2 opposes the population of Ranerou located on the positive coordinates to that of Labgar located on the negative coordinates:

- The individuals sampled in Ranerou are characterized by their size (D1.30 $=37.55 \pm 12.26 \mathrm{~cm})$, the thickness of their fruits and kernels $(1 . \mathrm{fr}=1.92 \pm 2.08 \mathrm{~cm}$ and $1 . \mathrm{am} 1.31 \pm 1.42 \mathrm{~cm})$ with a larger weight balance $(\mathrm{M} . \mathrm{fr}=4.38$ $\pm 1.32 \mathrm{~g}$; and M.p $=2.42 \pm 1.18 \mathrm{~g}$ );

- The individuals sampled in Labgar are characterized by a greater expression of leaf descriptors. Labgar leaves are longer $(\mathrm{W} . \mathrm{fe}=3.57 \pm 0.86 \mathrm{~cm})$ and wider $(\mathrm{W} . \mathrm{fe}=2.24 \pm 0.67 \mathrm{~cm})$.

Our results showed significant intra- and inter-site variability.

The variabilities observed in Labgar populations are lower (8.90\% [la.fr] to 35.44\% [Mn]) compared to those obtained in Ranerou (10.84\% [la.fr] to $48.80 \%$ [Mp]) and K. Alpha (14.90\% [la.fr] to $76.58 \%$ [Mn]).

Overall, the variabilities were greater for the variables pulp mass (Mp: 46.94\%) nut mass (Mn: 46.14\%), height of the living branch (Hbr: $38.61 \%$ ) and diameter of the individuals at breast height (D1.30: 34.71\%).

The results obtained indicate that the individuals sampled in Ranerou and those sampled in Koyli and present dendrometric characteristics close to those of Ranerou.

\subsection{Relationship between the different morphological descriptors}

The Pearson correlation matrix shows significant correlations between several pairs of variables (Table 2). These variables are very highly correlated: M.fr and M.p (96\%), L.fr and L.am (92\%), L.am/l.am and Lfr/lfr (89\%), L.fe and 1.fe (82\%), M.fr and la.fr (80\%). However, it is important to point out that strong correlations are observed within parameters belonging to the same characteristics (dendrometric characteristics, characteristics measured on leaves and those measured on fruit). Between these three groups of characteristics, the correlations were extremely low.

\subsection{Identification and characterization of subpopulations of Balanites}

In order to identify the most important variables for the discrimination of Balanites aegyptiaca populations, a principal component analysis (PCA) was carried out. Table 3 gives the eigenvalues and the percentage of variance of the first four (4) axes. 
Sam et al.

Morphological diversity of the populations of Balanites aegyptiaca L. Del in the Ferlo River in northern Senegal

Table 2: Correlation matrix between parameters measured on trees

\begin{tabular}{|c|c|c|c|c|c|c|c|c|c|c|c|c|c|c|c|c|c|}
\hline Variables & $\mathrm{D}_{1.30}$ & $\mathrm{Hbr}$ & Dhp & $\mathrm{Ht}$ & 1.fe & L.fe & $\begin{array}{l}\text { L.fe/ } \\
\text { 1.fe }\end{array}$ & la.fr & L.fr & $\begin{array}{l}\text { Lfr/ } \\
\text { lfr }\end{array}$ & 1.am & L.am & $\begin{array}{l}\text { L.am/ } \\
\text { l.am }\end{array}$ & M.fr & M.am & M.p & M.n \\
\hline $\mathrm{D}_{1.30}$ & 1.00 & & & & & & & & & & & & & & & & \\
\hline $\mathrm{Hbr}$ & 0.09 & 1.00 & & & & & & & & & & & & & & & \\
\hline Dhp & 0.65 & 0.39 & 1.00 & & & & & & & & & & & & & & \\
\hline $\mathrm{Ht}$ & 0.47 & 0.39 & 0.73 & 1.00 & & & & & & & & & & & & & \\
\hline 1.fe & -0.18 & -0.04 & -0.01 & -0.06 & 1.00 & & & & & & & & & & & & \\
\hline L.fe & -0.13 & 0.13 & 0.09 & 0.02 & 0.82 & 1.00 & & & & & & & & & & & \\
\hline L.fe/l.fe & 0.10 & 0.22 & 0.13 & 0.18 & -0.69 & -0.22 & 1.00 & & & & & & & & & & \\
\hline la.fr & 0.17 & 0.12 & 0.02 & 0.14 & -0.12 & -0.18 & -0.09 & 1.00 & & & & & & & & & \\
\hline L.fr & 0.08 & 0.18 & 0.19 & 0.29 & 0.13 & 0.10 & -0.08 & 0.25 & 1.00 & & & & & & & & \\
\hline Lfr/lfr & -0.07 & 0.08 & 0.15 & 0.15 & 0.20 & 0.24 & 0.01 & -0.54 & 0.67 & 1.00 & & & & & & & \\
\hline 1.am & 0.12 & 0.14 & 0.13 & 0.22 & 0.03 & 0.00 & -0.10 & 0.72 & 0.14 & -0.41 & 1.00 & & & & & & \\
\hline L.am & 0.05 & 0.13 & 0.23 & 0.32 & 0.21 & 0.19 & -0.09 & 0.09 & 0.92 & 0.72 & 0.15 & 1.00 & & & & & \\
\hline L.am/l.am & -0.05 & 0.02 & 0.10 & 0.11 & 0.14 & 0.16 & 0.00 & -0.41 & 0.67 & 0.89 & -0.56 & 0.73 & 1.00 & & & & \\
\hline M.fr & 0.21 & 0.11 & 0.16 & 0.23 & -0.06 & -0.09 & -0.02 & 0.80 & 0.49 & -0.18 & 0.65 & 0.42 & -0.09 & 1.00 & & & \\
\hline M.am & 0.09 & 0.16 & 0.17 & 0.29 & 0.09 & -0.01 & -0.18 & 0.68 & 0.51 & -0.07 & 0.76 & 0.46 & -0.13 & 0.76 & 1.00 & & \\
\hline M.p & 0.23 & 0.08 & 0.14 & 0.17 & -0.12 & -0.11 & 0.06 & 0.73 & 0.41 & -0.21 & 0.50 & 0.33 & -0.06 & 0.96 & 0.53 & 1.00 & \\
\hline M.n & 0.14 & 0.01 & 0.07 & 0.14 & 0.10 & 0.08 & -0.14 & 0.59 & 0.15 & -0.32 & 0.60 & 0.08 & -0.34 & 0.55 & 0.55 & 0.47 & 1.00 \\
\hline
\end{tabular}

CV: Coefficient of variation ; Dhp: Crown diameter ; Ht :Total height; D1.30 : Diameter at 1.30 m; Hbr: height of the first branch; Dhp: crown diameter; 1.fe: leaf width; L.fe: length of leaves; la.fr: fruit width; L.fr: length of fruit; 1.am: width of the almond; L.am: length of the almond; M.fr: mass of the fruit; M.am: mass of almond; M.p: pulpe mass; M.n: mass of the nut

Table 3: Eigenvalues and percentage change in the first four axes of the CPA

\begin{tabular}{lcccc}
\hline & F1 & F2 & F3 & F4 \\
\hline Eigenvalues & 5.029 & 3.771 & 2.462 & 1.850 \\
Variability (\%) & 29.580 & 22.184 & 14.484 & 10.882 \\
cumulative \% & 29.580 & 51.764 & 66.248 & 77.130 \\
\hline
\end{tabular}

These first four axes alone explain $77.13 \%$ of the total variance. The first axis accounts for $29.58 \%$ of the variance, the second axis $22.18 \%$, the third axis $14.48 \%$ and the fourth axis $10.88 \%$. Analysis of the contribution of the variables to the different axes (Table 4) allows us to select the most relevant ones.

Table 4: Contribution of variables $(\%)$ to the different axes of the PCA $(\mathrm{p}<0.0001)$

\begin{tabular}{l|ccc|c}
\hline Variables & F1 & F2 & F3 & F4 \\
\hline Hbr & 1.11 & 0.99 & 4.51 & 6.06 \\
D1.30 & 2.10 & 0.05 & $\mathbf{1 1 . 9 2}$ & 7.39 \\
Dhp & 2.17 & 2.63 & $\mathbf{1 2 . 1 0}$ & $\mathbf{1 8 . 6 8}$ \\
Ht & 3.57 & 2.79 & $\mathbf{1 0 . 7 8}$ & $\mathbf{1 0 . 7 5}$ \\
l.fe & 0.01 & 2.88 & $\mathbf{2 3 . 4 5}$ & $\mathbf{1 5 . 0 5}$ \\
L.fe & 0.05 & 3.40 & $\mathbf{1 0 . 9 6}$ & $\mathbf{1 7 . 2 8}$ \\
L.fe/l.fe & 0.06 & 0.15 & $\mathbf{2 0 . 2 8}$ & 3.10 \\
la.fr & $\mathbf{1 4 . 2 0}$ & 3.33 & 0.36 & 0.91 \\
L.fr & 5.15 & $\mathbf{1 5 . 8 5}$ & 0.15 & 4.54 \\
Lfr/lfr & 0.79 & $\mathbf{2 3 . 1 2}$ & 0.01 & 1.16 \\
l.am & $\mathbf{1 2 . 6 0}$ & 2.55 & 1.08 & 0.96 \\
L.am & 3.77 & $\mathbf{1 8 . 5 2}$ & 0.32 & 2.47 \\
L.am/l.am & 0.64 & $\mathbf{2 2 . 0 2}$ & 0.07 & 4.09 \\
M.fr & $\mathbf{1 7 . 0 5}$ & 0.00 & 0.12 & 2.74 \\
M.am & $\mathbf{1 4 . 5 2}$ & 0.12 & 1.50 & 0.10 \\
M.p & $\mathbf{1 3 . 2 6}$ & 0.04 & 0.01 & 4.02 \\
M.n & $\mathbf{8 . 9 6}$ & 1.55 & 2.38 & 0.70 \\
\hline
\end{tabular}

Dhp: Crown diameter ; Ht :Total height; D1.30 : Diameter at $1.30 \mathrm{~m}$; Hbr: height of the first branch; Dhp: crown diameter; 1.fe: leaf width; L.fe: length of leaves; la.fr: fruit width; L.fr: length of fruit; 1.am: width of the almond; L.am: length of the almond; M.fr: mass of the fruit; M.am: mass of almond; M.p: pulpe mass; M.n: mass of the nut 
Examination of Table 4 indicates that the fruit variables provide more information to the first two axes of the PCA. These are the ratio between the length and width of the fruit and the almond ( $\mathrm{Lfr} / \mathrm{lfr}$ and L.am/l.am), the length of the fruit and the almond (L.am and L.fr), the mass of the fruit, the almond and the pulp (Mfr, M.am and M.p), the mass of the nut and the width of the fruit and the almond (M.n, l.fr, l.am). The dendrometric parameters (trunk diameter at $1.30 \mathrm{~m}$ (D1.30), crown diameter and total height (Dhp and $\mathrm{Ht}$ )) and those measured on the leaves (leaf length and width (L.fe and l.fe ), the ratio between leaf length and width (L.fe/l.fe ), contribute to the formation of axes 3 and 4. However, their contribution to the formation of axis 3 is greater with two additional variables, hence the choice of axis 3 to present the second factorial plane (F1xF3).

The dispersion of sampled individuals in the planes generated by the first three axes of the PCA (F1x F2 and F1xF3) made it possible to describe the morphological features of the Balanites aegyptiaca populations (Fig. 5).

Six (6) groups can be distinguished by examining Figures 5 and 6 . The individuals that make up the groups are those whose relative contribution to axis formation is significant and mentioned as significance in the PCA (p < $0.0001)$.

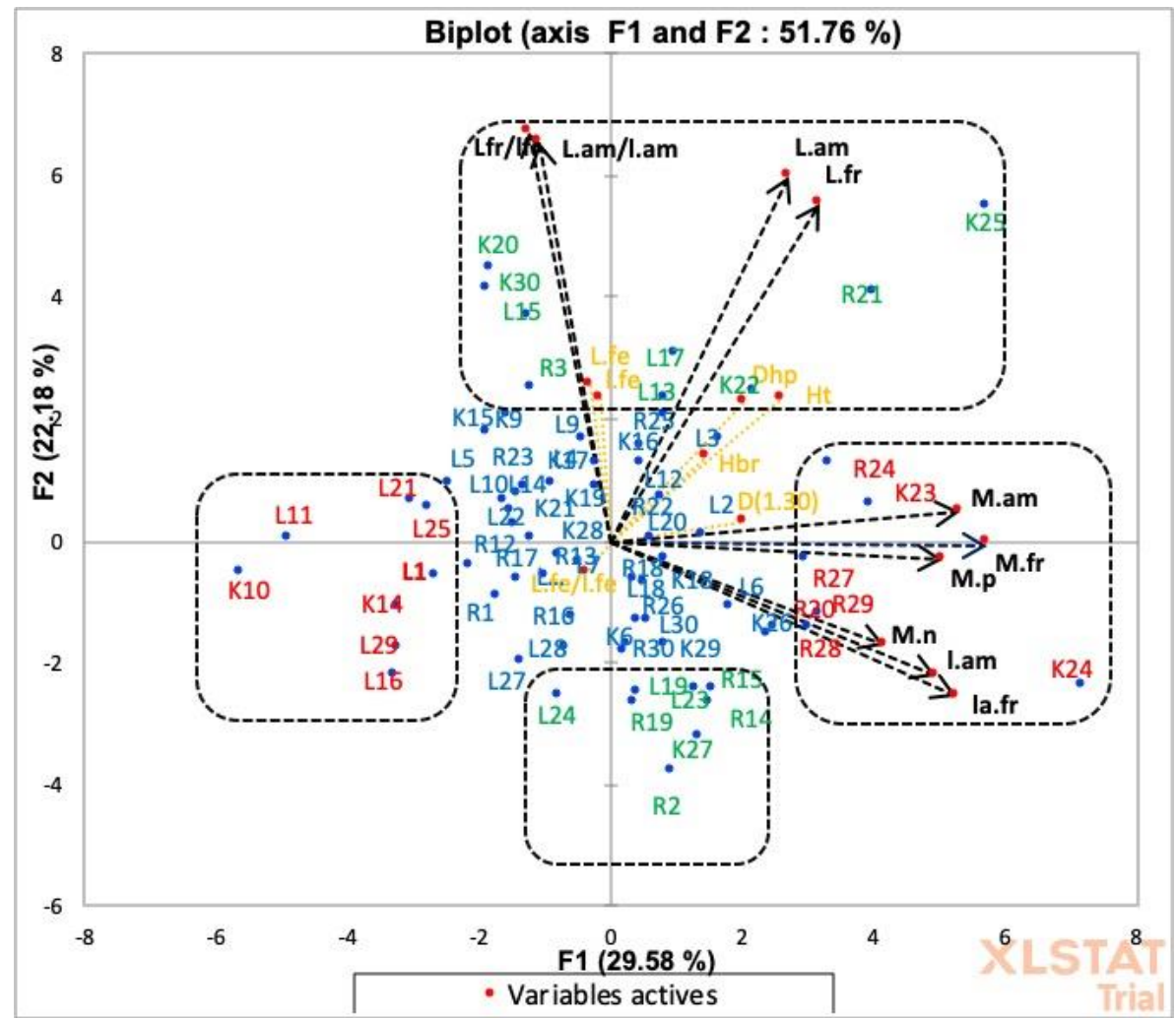

Figure 5: Distribution of B. aegyptiaca individuals on the plane defined by axes 1 and 2 of the PCA (K=Koyli Individuals; $\mathrm{R}=$ Ranerou Individuals; $\mathrm{L}=$ Labgar Individuals; $1,2,3 \ldots 30=$ numbers of individuals)

Analysis of Figure 5 shows that the first two axes of the PCA are associated with the fruit variables:

- axis 1 presents on the positive coordinates the group 1 ( Gr1) composed of individuals with large fruits (l.fr and high 1.am) with particularly important weight characteristics (M.fr, M.p, M.am and M.n). Group 1 is opposed to group $2(\mathrm{G} 2)$ located on the negative chordates. It consists of individuals producing small fruits with particularly low weight characteristics (M.fr, M.p, M.am and M.n);

- axis 2 has group 3 (Gr3) on the positive chordates. This group is characterised by individuals producing long (L.fr) and long almond (L.am) fruits. The fruits of this group are longer than wide (high L.fr/l.fr and L.am/l.am). Group 3 contrasts with group 4 (Gr4) located on the negative coordinates of the axis. It is composed of individuals, which produce small fruits. Detailed examination of their dimensions shows that for these fruits the quotient L.fr/l.fr and L.am/l.am is approximately equal to unity. The fruits in question are rounded in shape.

Axis 3 of the PCA (Figure 6) is associated with the dendrometric parameters and leaf variables. This axis presents on the positive coordinates the opposite of group five (Gr.5). This group presents individuals characterized by significant leaf development (L.fe and l.fe). Group five (Gr.5) contrasts with group six (Gr.6) located on the negative coordinates of the axis. It consists of individuals characterised by a high development of the dendrometric descriptors (D1.30, Dhp and Ht) and whose leaves are longer than wide (high L.fe/l.fe). 
Table 5 shows the composition of the discriminated groups as well as the geographical distribution of the individuals constituting them.

The balance sheet of the CPA presented in Table 5 shows that:

- the Ranerou site is mainly characterized by individuals producing large fruits with a high weight balance (Gr 1) associated with individuals producing rounded fruits $(\mathrm{Gr} 4)$;

- the Labgar site is characterized by individuals with large leaves (Gr 5) producing long and rounded fruits and almonds (Gr 3 and 4);

- the Koyli Alpha site is characterized by individuals characterized by a high development of vegetative traits ( $\mathrm{Gr}$ 6) and individuals producing long fruits and almonds ( $\mathrm{Gr} 3$ ). This site contains individuals producing fruits characteristic of group 1 and 2 .

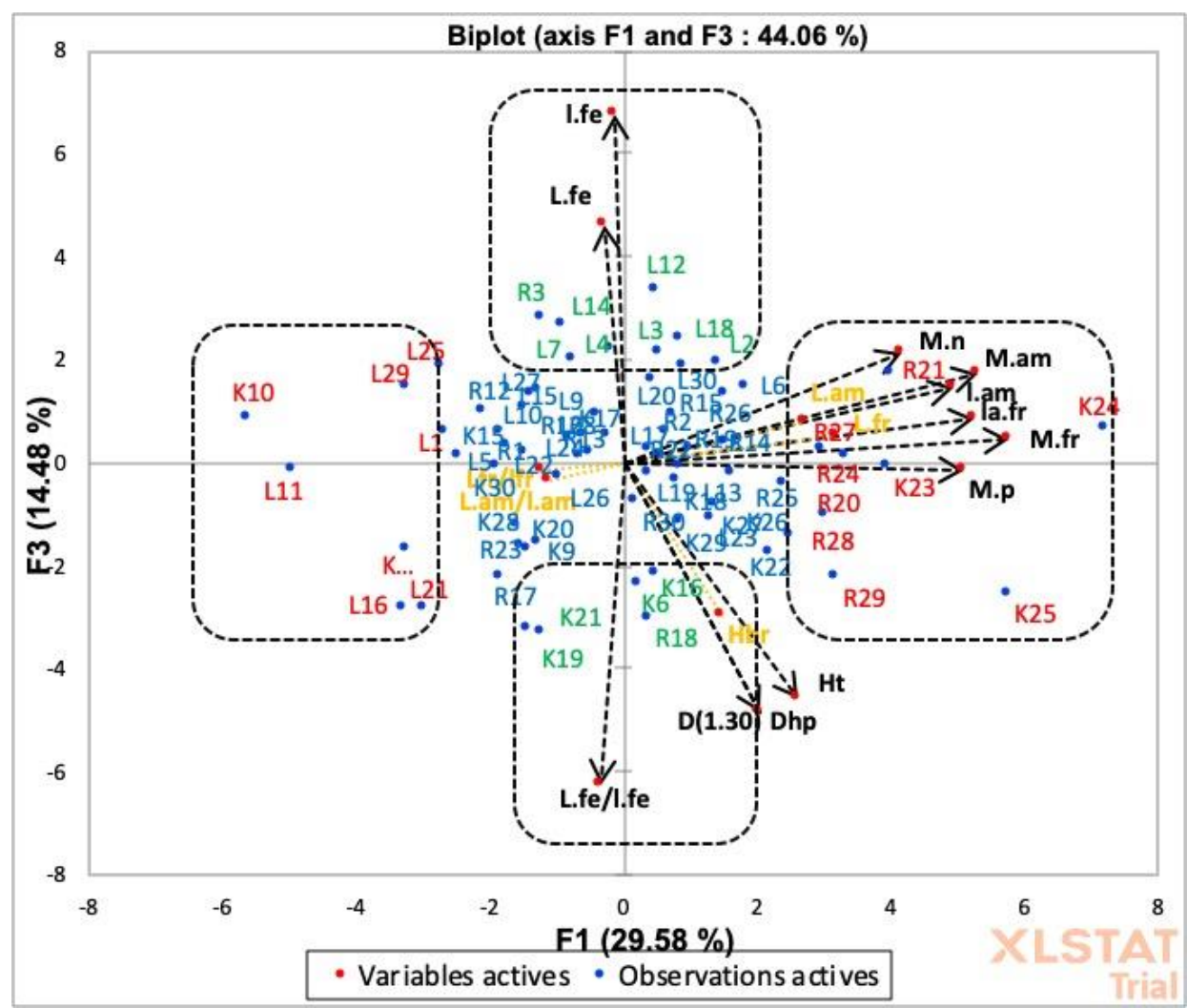

Figure 6: Distribution of B. aegyptiaca individuals on the plane defined by axes 1 and 3 of the PCA (K=Koyli Individuals; $\mathrm{R}=$ Ranérou Individuals; $\mathrm{L}=$ Labgar Individuals; $1,2,3 \ldots 30=$ numbers of individuals)

Table 5: Composition, distribution and characteristics of groups

\begin{tabular}{|c|c|c|c|c|c|}
\hline \multirow{2}{*}{$\begin{array}{l}\text { Groups } \\
\text { (Gr) }\end{array}$} & \multirow{2}{*}{ Composition } & \multicolumn{3}{|c|}{ Répartition } & \multirow{2}{*}{ Caractéristiques } \\
\hline & & K. A & $\mathrm{L}$ & $\mathrm{R}$ & \\
\hline Gr 1 & $\begin{array}{l}\text { K23, K24, R20, } \\
\text { R24, R27, R28, } \\
\text { R29. }\end{array}$ & 2 & 0 & 5 & $\begin{array}{l}\text { - Big fruits: I.fr and I.am high } \\
\text { - High masses: M.fr, M.p, M.am and M.n }\end{array}$ \\
\hline Gr 2 & $\begin{array}{l}\text { K10, K14, L1, L11, } \\
\text { L16, L21, L29. }\end{array}$ & 2 & 5 & 0 & - Low masses: M.fr, M.p, M.am and M.n \\
\hline Gr 3 & $\begin{array}{l}\text { K20, K22, K30, } \\
\text { L13, L15, L17, } \\
\text { R21. }\end{array}$ & 3 & 3 & 1 & - Fruits and long almonds (L.fr and L.am) \\
\hline Gr 4 & $\begin{array}{l}\text { K27, L19, L23, } \\
\text { L24, R2, R15, R14, } \\
\text { R19. }\end{array}$ & 1 & 3 & 4 & $\begin{array}{l}\text { - Rounded fruit and almond } \\
\text { (L.fr/I.fr and L.am/l.am } \approx 1 \text { ) }\end{array}$ \\
\hline Gr 5 & $\begin{array}{l}\text { L2, L3, L4, L7, } \\
\text { L12, L14, L18, R3 }\end{array}$ & 0 & 7 & 1 & - Long and wide leaves (L.fe and I.fe) \\
\hline Gr 6 & $\begin{array}{l}\text { K6, K16, K19, K21, } \\
\text { R18. }\end{array}$ & 4 & 0 & 1 & $\begin{array}{l}\text { - Developed individuals (D1.30, Dhp and Ht) } \\
\text { - Elongated leaves (high L.fe/I.fe) }\end{array}$ \\
\hline
\end{tabular}




\subsection{Morphological proximities between individuals discriminated by PCA}

An ascending hierarchical classification (AHC) was performed in order to examine the morphological proximity of individuals discriminated by PCA. The dendrogram obtained using Ward's aggregation method (Figure 7) shows three classes $(\mathrm{C} 1, \mathrm{C} 2$ and $\mathrm{C} 3)$.

Class 1 contains a greater number of individuals (35) followed by class 2 (29 individuals) and class 3 (7 individuals) with respectively $59.49 \%, 72.91 \%$ and $50.91 \%$ intra-class variability. Class 2 thus presents a greater morphological heterogeneity compared to the others. The dendrogram indicates a very heterogeneous distribution of individuals discriminated by PCA. However, a certain similarity is observed between individuals in groups 1, 2, 3 and 5.

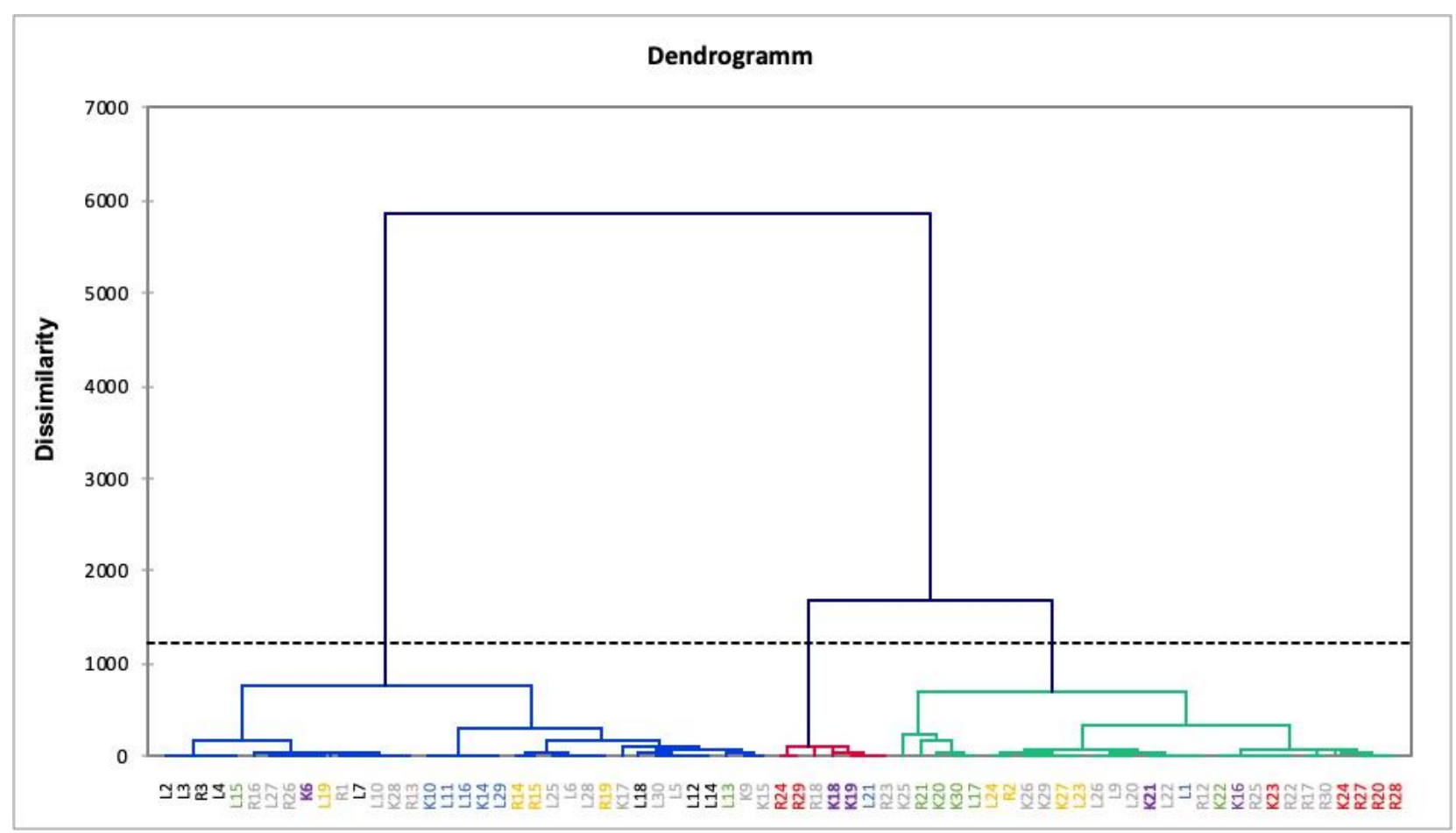

Figure 7: Ascending Hierarchical Classification (AHC) according to Ward's aggregation criteria $(\mathrm{Gr}=\mathrm{Group} ; \mathrm{C}=$ Class)

\subsection{Discussion}

In order to valorize the genetic resources of Balanites aegyptiaca, a study was carried out on the morphometric characteristics of the species' population in the Ferlo zone in northern Senegal. Morphological analysis is indeed the initial phase of description of genetic resources and contributes significantly to the varietal selection process (Ouedraogo, 1995).

The results obtained within the framework of this study showed significant differences in the descriptors used at the intra- and inter-site levels. Dendromorphological descriptors (height, diameter at breast height, crown diameter) are more developed in Ranerou and Koyli Alpha; in contrast to the Labgar population characterized by a low expression of dendromorphological descriptors. This indicates a greater maturity of the Ranerou and Koyli Alpha populations compared to the Labgar Zone population. This greater maturity of the B. aegyptiaca populations in the drier northern part (Koyli Alpha) could be explained by the proximity of one of the Ferlo valleys, which may have a positive influence on the development of woody plants. In Ranerou, on the other hand, the positive impact of the Ferlo valley is combined with the greater seasonal water balance in the South-Eastern part of the Ferlo.

The water deficit at the northern sites impacted the morphology of the leaves of Koyli Alpha. Indeed the high ratio of L.fe/l.fe indicates that the leaves are longer than wide. This leaf elongation considered as an adaptation to drought and known as xerophytism allows trees to reduce water loss through transpiration (Killian and Lemée, 1956; Oppenheimer, 1961). In Labgar, on the other hand, the leaves produced by individuals are highly developed. It is surprising that they are more developed than those at Ranerou, which is the wettest site on the transect. However, the edaphic contrast, described by Leprun (1971), between the Ranerou site (lateritic) and the Labgar site (sandy) could have an impact on leaf morphology. Globally, the high variability of certain morphological characteristics of $B$. aegyptiaca populations in Ferlo could be linked to the sensitivity of morphological descriptors to environmental 
conditions, as shown by the work of Abdou Habou et al. (2020) in Niger. The structure of the B. aegyptiaca du Ferlo would thus be adapted to local ecological conditions. According to Lawn (1989), an understanding of the effects of the environment and their interaction with plants allows research on genetic and agronomic improvements of the plant to be better directed.

The characteristics of the ecosystems of the Southeast (Ranerou) seem to have a beneficial influence on the quality of the fruits produced by the B. aegyptiaca. Indeed, individuals from this area produce large fruits with a better weight balance (M.fr and M.p) compared to Labgar and Ranerou fruits. According to Gutterman, (2000), environmental conditions, such as water deficit, temperature and nutritional capacity of the soil are factors that negatively influence the performance of individuals during reproduction.

Analysis by main component of morphological characteristics showed that correlations between the different groups of characteristics (dendrometric, fruit and leaf) are not well established. This indicates the impossibility to identify morphotypes by combining several morphological traits of the species as was so well specified by Leakey et al. (2005).

For all the parameters measured, the morphological characteristics of the fruits were more discriminating. These results confirm the observations of the Ferlo populations for which the descriptor related to fruit morphology was highly cited (31.4\%) to characterize the population of the species in Ferlo (Sagna, 2014a). Similar work carried out by Abasse et al. (2011), Soloviev et al. (2004) and Abdoulaye et al. (2016) corroborates our results. Their work also showed that fruit mass varies significantly according to ecological zone.

The principal component analysis discriminated a group (Group 1) of particular interest for the morphology and mass of its fruits. Group 1 consists mainly of individuals from the South-East (Ranerou). These results also corroborate those of (Abasse, 2011) which states that B. aegyptiaca in the wettest parts of the sample region tends to have heavier grains and fruit mass varies significantly according to ecological zone. It can therefore be considered that the agronomic potential of group 1 individuals could be of interest for a breeding program for the species although subject to the influence of environmental conditions. In Tunisia, the characterization of fruits of Phoenix dactylifera L. (Arecaceae) in the Djerid region has enabled the selection of varieties with large fruits, interesting masses and high pulp content for the date industry (Reynes et al., 1994).

Variations observed within the B. aegyptiaca population at the same site suggest the existence of genomes, or could be explained by topography-related variability (Fandahan et al., 2010). Even if the dendrogram resulting from the hierarchical ascending classification (AHC) did not show the closeness of all the groups discriminated by the PCA, it nevertheless showed a clear similarity between individuals of groups 1,2, 3 and 5. This means that they could be genetically very close. An analysis of the plant genome could provide information on the genetic nature of these sub-populations.

\section{CONCLUSION}

This study was conducted on the population of Balanites aegyptiaca at Ferlo with the aim of characterizing the species' population and identifying individuals that could be targeted by a varietal selection program.

The results obtained showed that the morphological characteristics of the species are largely influenced by the variability related to environmental conditions. However, it is likely that the variation in these characteristics is genome-related given the variabilities obtained within populations at the same site.

The lack of correlations between groups of descriptors (dendrometric, fruit and leaf) compromises any chance of combining a wide range of traits for the description of morphotypes in the species.

Of all the descriptors used, those relating to fruit are more discriminating. They made it possible to identify a group of individuals that could be of interest to a varietal selection program in view of the mass and morphology of the fruits they produce.

As with dendrometric characteristics, the agro-morphological characteristics of fruits are linked to the variability of environmental conditions. Within the wetter Ranerou population, individuals were located that could be of interest for a varietal selection program given the morphology and mass of the fruits they produce.

A study of ecological factors (soil and geomorphology) as well as genetic factors influencing morphological variation would be necessary in order to identify their implications for the selection, conservation and genetic improvement of the species.

\section{Acknowledgements}

The authors would like to thank the Future Sahel project and the Total Foundation for funding this work. To these thanks, we associate the UMI 3189 and the OHMi of Tessékéré, for their involvement in the good organization of the field missions. 
Conflict of Interest

Authors declare that there is no conflict of interest.

\section{REFERENCES}

Abdoulaye, B., Bechir, A.B., Mapongmetsemi, P.M. (2016). Morphological variability of Balanites aegyptiaca (L.) Del. in the Ouaddaï region of Chad International. Journal of Biological Chemical Sciences, 10 (4), 1733-1746.

Abdou Habou, M.K., Abdou, L., Rabiou, H, Garvi, J., Ibrahim Mamadou, M., Kaka Kiari, B.K., Mahamane, A. (2020). Variability of the morphological characters of Balanites Aegyptiaca (L.) Del. based on the climatic gradient of Zinder region (East-Central Niger). International Journal of Development Research, 10(01), 3330933315.

Abasse T., Weber, J.C., Katkore, B., Boureima, M., Larwanou, M., Kalinganire, A. (2011). Morphological variation in B. aegyptiaca (L.) Del. Fruits and seeds withing and among parkland agroforests in eastern Niger. Agrofor. Syst., 81, 57-66. DOI: 10.1007/s10457-010-9323-x.

Arbonnier, M. (2000). Trees, shrubs and lianas in the dry areas of West Africa. CIRAD-MNHN-UICN, France.

Berhaut, J. (1979). Illustrated flora of Senegal. Vol. 6, Dakar: Government of Senegal, Ministry of Rural Development and Hydraulics, Directorate of Water and Forestry. Clairafrique Edition.

Chevallier, M.H., Bensaid, S., Diallo, O.B., Sahki, R., Ganaba, S., Sanou, J., Bouguedoura, N., Vaillant, A., Babin, D. (2003). Biodiversity and multidisciplinarity: methodology for drylands. Bois et forêts des tropique, 276(2), $33-41 \mathrm{p}$.

Fandohan, B., Assogbadjo, A.E., Kakaï, R.G., Kyndt, T., Sinsin, B. (2010). Quantitative morphological descriptors confirm traditionally classified morphotypes of Tamarindus indica L. fruits. Genetic Resources and Crop Evolution, 58, 299-309.

Elfeel, A.A., Hindi, S.Z. (2014). Balanites aegyptiaca (L.) Del. var. aegyptiaca seed composition and variability among three different intraspecific sources. Life Science Journal, 11(7).

Graudal, L. (1998). Development of a national strategy and action plan for the conservation of forest genetic resources. Presentation at the regional training workshop on the conservation and sustainable use of forest genetic resources. Ouagadougou, Burkina Faso.

Gutterman, Y. (2000). Environmental factors and survival strategies of annual plant species in the Negev Desert, Israel. Plant Species Biology, 15, 113-25.

Hall, J.B., Walker, D.H. (1991). Le Balanites aegyptiaca (L) Del: A monograph. Bangor ; Sch Agri For Sc Univ Wales.

Kebe, I.M. (2019). Characterization of the soil, climate and woody vegetation on a section of the Great Green Wall at Ferlo Nord. Master's thesis, University. Cheikh Anta Diop, Dakar, Senegal.

Kouyate, AM. (2005). Ethnobotanical aspects and study of the morphomogical, biochemical and phenological variability of Detarium microcarpum Guill. \& Perr. in Mali. Thesis, University of Ghent, Belgium.

Killian, C., Lemée, G. (1956). Xerophytes: their water savings. In : Handbuch der Pflanzenphysiologie (W. Ruhland, ed.), Springer-Verlag, Berlin, 3, $787-824$.

Lawn, R.J. (1989). Agronomic and physiological constraints to productivity of tropical grain legumes and opportunities for improvement. Experimental agriculture, 25(4), 509-528.

Leprun, JC. (1971). New observations on the fixed sand dune formations of Ferlo Nord occidental (Senegal). Ass. Senegal, Et. West African Quaternary, Bull. Liaison, Senegal, 31, 69-78 pp.

MEPN. (2008). Some lessons on the social and historical economy of the Ferlo pastors. Capitalization of the PAPF /Senegal project.

Oppenheimer, H.R. (1961). Adaptation to drought: xerophytism. In: Arid Zone Research, Unesco, XV, 115- 153.

Sagna, M.B., Diallo, A., Ndiaye, O., Goffner, D., Guisse, A. (2014a). Biochimical and nutritional value of Balanites aegyptiaca (L) Del fruit pulps from Northen Ferlo in Senegal. AJB, 13(2), 336-342.

Sagna, M.B., Niang, K., Guisse, A., Goffner, D., (2014b). Ecological and ethnobotanical knowledge of Balanites aegyptiaca (L.) Del. by local populations in the Ferlo region in the north of Senegal. Biotechnologie, Agronomie, Société et Environnement, 18 (4), 503-511.

Sagna, M.B. (2015). Ethnobotany, ecology, phenological monitoring and physico-chemical and nutritional characteristics of the desert date palm (Balanites aegyptiaca (L.) Del.) in the Ferlo in northern Senegal. Thesis thesis, Cheikh Anta Diop University, Dakar, Senegal.

Soloviev, P., Niang, T.D., Gaye, A., Totte, A. (2004). Variability in the physico-chemical characteristics of the fruits of three woody species harvested in Senegal. Adansonia digitata, Balanites aegyptiaca et Tamarindus indica. Fruits, 109-119. 